\title{
The Role of the iPad Tablet in Higher Education Science Teaching
}

\author{
Sandra Domjanić Drozdek ${ }^{1 \star}$, Lana Feher Turković ${ }^{1}$, Ana Mojsović Ćuić ${ }^{1}$, Ozren Digula ${ }^{1}$
}

${ }^{1}$ University of Applied Health Sciences, Zagreb, CROATIA

*Corresponding Author: sandra.domjanic-drozdek@zvu.hr

Citation: Domjanić Drozdek, S., Feher Turković, L., Mojsović Ćuić, A. \& Digula O. (2020). The Role of the iPad Tablet in Higher Education Science Teaching. Pedagogical Research, 5(1), em0051. https://doi.org/10.29333/pr/6339

\section{ARTICLE INFO}

Received: 3 Oct. 2019

Revised: 2 Nov. 2019

Accepted: 2 Nov. 2019

\begin{abstract}
At the University of Applied Health Sciences, the iPad tablets are used at the undergraduate professional study programs Environmental Health Engineering and Laboratory Medical Diagnostics as part of the practical classes in Biology and Chemistry. Four applications are used within the framework of the unit titled "Preparing Solutions", "Periodic Table", "Molarity", "Chemist" and "Beaker". Within the class on Biology, tablet computer applications are used to cover subject matter dealing with Genetics and Cell Structure (application "Cytogenetics", "Diseases and disorders", "Gene Screen", "Population Genetics" and "Cell World"). Though e-teaching certainly cannot replace the classic course teaching, it is greatly beneficial for easier acquiring of the course subject matter.
\end{abstract}

Keywords: iPad, higher education, chemistry, biology

\section{INTRODUCTION}

The rapid development of information technology and its application during the last decades have left teachers faced with new challenges at all levels of education, ranging from elementary school to higher education. Increasingly sophisticated information technology used both in business and social contexts has put teachers in a situation to acquire it (at best) simultaneously with Generation Z or iGeneration students, to find new ways of communicating and to evaluate its potential, advantages, downsides and limitations. The development of mobile learning kicked off after e-learning and it refers to the advantages afforded by mobile technologies such as the latest generation of mobile telephones and tablet computers. Such technologies have the potential to fundamentally change the ways that learning and teaching are carried out, greatly favoring constructivist and collaborative approaches to learning, and flexible and adaptive approaches to teaching (Manuguerra \& Petocz, 2011).

Although the first generation of iPad was launched in January 2010, the iPad has been widely used in education and its application is being assessed. There are numerous advantages of using the iPad: using the iPad in class alters the teaching process dynamics and how the teacher interacts with students, it fosters creative research into a particular matter, encourages perseverance when solving more complex problems, changes the learning experience and enables students to take an active role in classes. Students are not merely passive receivers, but rather they get to be engaged (to a certain extent) and determine how deeply they are going to delve into a certain matter. They can share ideas and material thereby creating their learning and encourage each other to work (Godsk, 2013; Lukša et al., 2014).

The handling itself is straightforward, while the devices are small in size and mobile. They enable students to personalize particular contents - take photos, download files, send content via email, search databases, etc. There are considerable environmental advantages of using a tablet device whereby printing and paper use are reduced and energy is conserved (Jennings et al., 2011).

As far as downsides go, it is important to note that during class it is difficult to simultaneously control the students' social contacts due to easier access to social networks, email and messaging (Rossing et al., 2012).

At the University of Applied Health Sciences students have been using iPad applications as part of the practical classes in Anatomy, Physiology, Biology and Chemistry for several years, therefore, University of Applied Health Sciences became the Apple Regional Training Center in 2016. iPad tablets are used at the undergraduate professional study programs of Environmental Health Engineering and Laboratory Medical Diagnostics as part of the practical classes in Biology and Chemistry. 


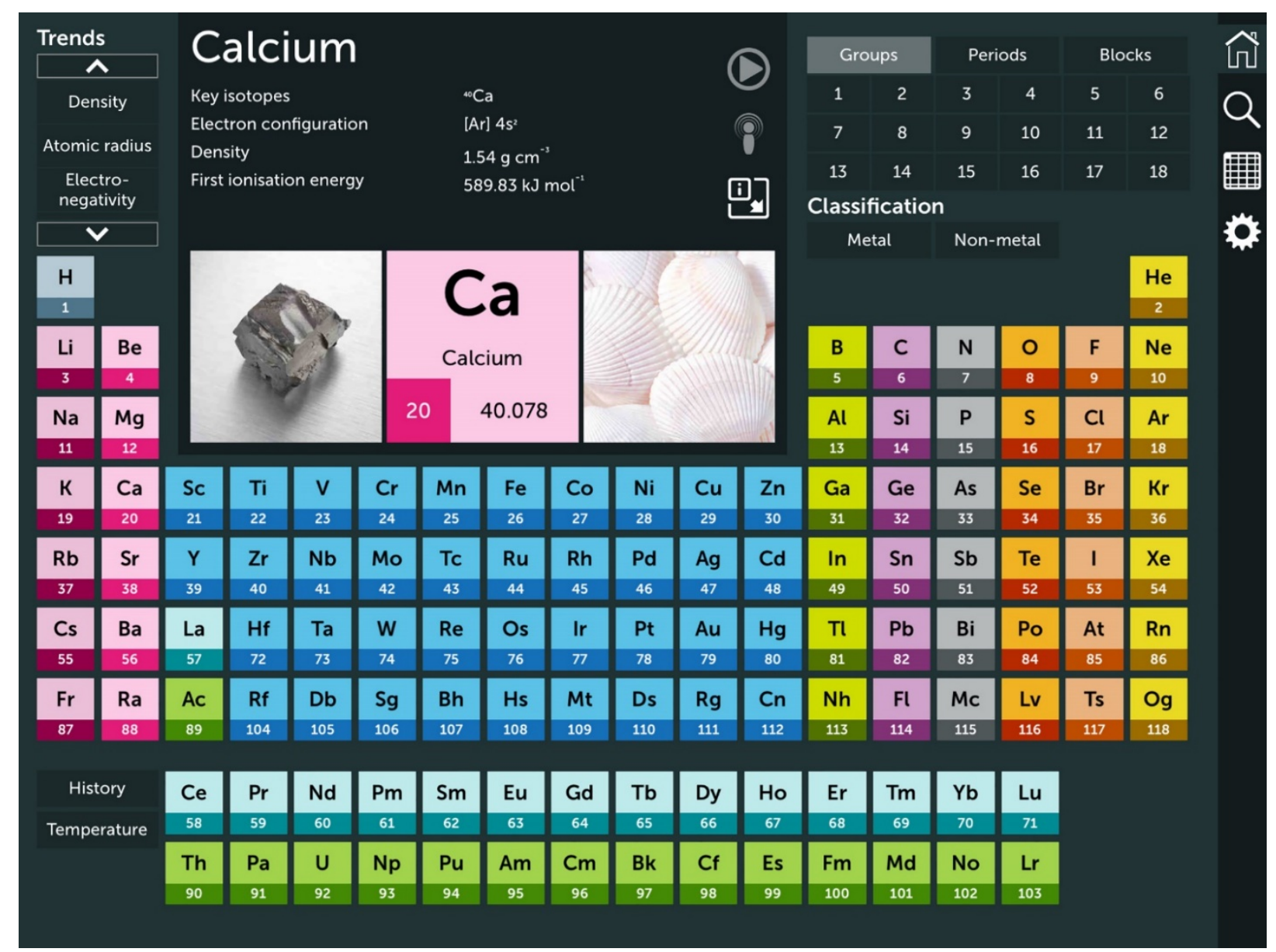

Figure 1. The application's interface when selecting the chemical element of calcium (application Periodic Table version 1,4 $\subset$ Royal Society of Chemistry 2015)

\section{APPLICATIONS IN SCIENCE TEACHING}

\section{Applications in Practical Chemistry Classes}

Four applications are used within the framework of the unit titled Preparing "Solutions". They are the following: "Periodic Table", "Molarity", "Chemist" and "Beaker". The unit "Preparing Solutions" encompasses both computational and experimental work. Each student is assigned four different problems with the aim of preparing solutions with the given composition. They need to prepare set volumes or masses of sodium chloride, hydrochloric acid, copper(II) sulfate and sodium sulfate solutions with the given mass concentration or amount concentration, mass share or molarity. In order for the students to be able to prepare the given solutions, they need to calculate the mass or volume of particular salts or acids for which they need the elements' relative atomic mass from the periodic table where the "Periodic Table" application is used. By using the application "Molarity" they can check whether the calculations are accurate. The "Chemist" application is used to demonstrate explosive chemical reactions to students such as the reaction of sodium with water, where the given experiment is simulated in a safe environment. "Beaker" is an application that enables two iPad devices to interact and demonstrates chemical reactions in an innovative way. It is used for reactions between compounds not found in the laboratory.

In addition to element symbols and names, the mobile application "Periodic Table" contains imagery depicting how a particular element may be used in everyday life (Figure 1) and gives an interactive overview of how the elements change state as temperature increases. The application gives an insight into their properties, such as melting point, boiling point, density, electronegativity, relative atomic mass, electronic configuration, etc. By touching a particular chemical element, they gain access to a whole range of information (Figure 2) on each element, which in turn enables students to conduct active research, depending on their individual interests thereby acquiring new insight and improving existing knowledge under the course teacher's professional guidance.

The mobile application "Molarity" is a chemistry calculator tool that generates lab-ready directions describing how to prepare an acid or base solution of a specified molarity or normality from a concentrated acid or base solution. You can select the acid or base in the start menu and you can enter the desired volume or concentration parameters (Figure 3) and then the application suggests the solution. A second tab includes a general molarity function that calculates the mass of any reagent needed to prepare a given volume of solution of desired molarity. A third tab features a stock dilution function that calculates how to dilute a stock solution of any known molarity to your desired volume and molarity. The "Molarity" application is used by students upon independently solving the problems and they then validate the obtained results by entering the given parameters. 


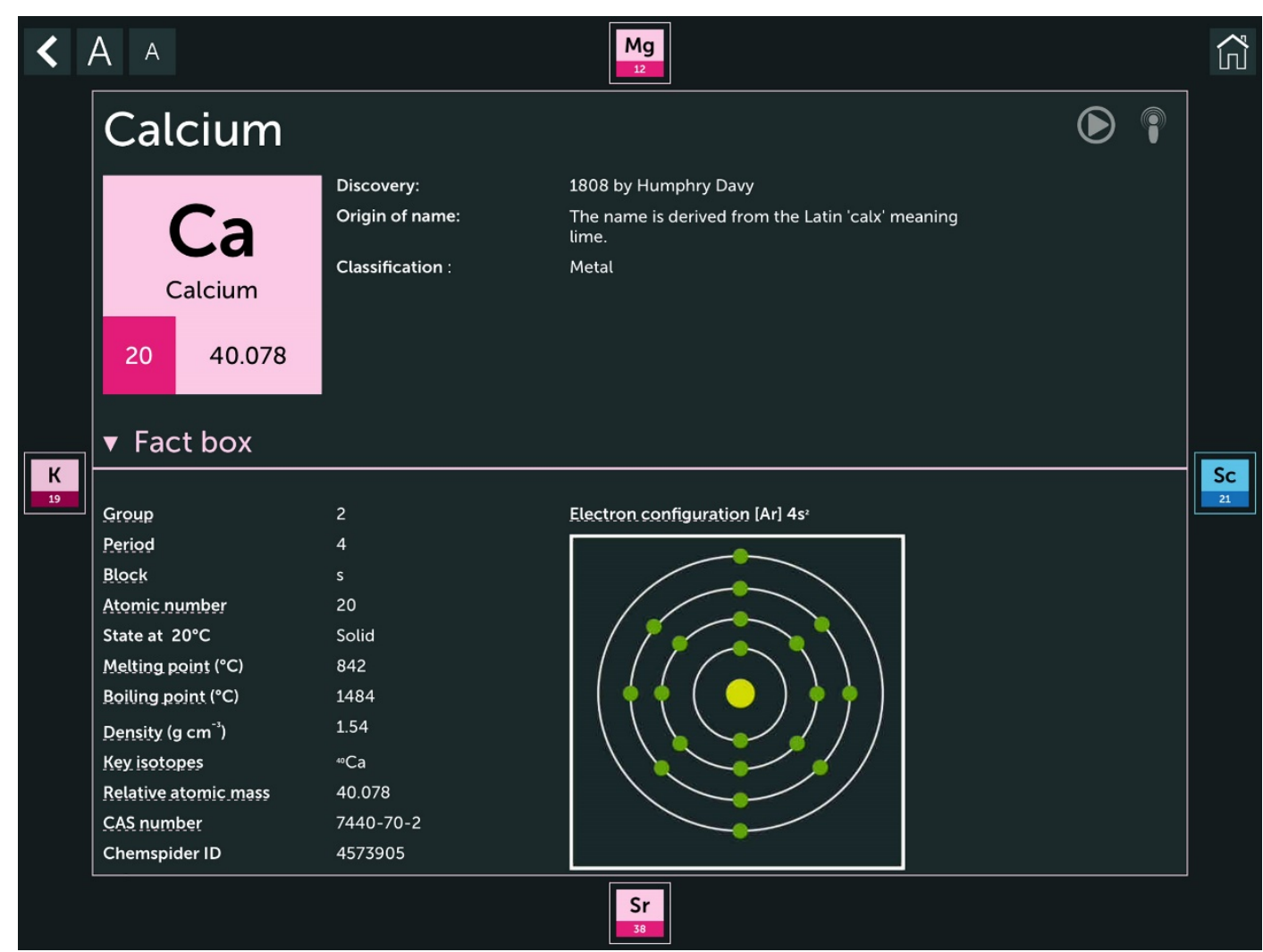

Figure 2. The application's interface when selecting the main menu icon (application Periodic Table version 1,4 @Royal Society of Chemistry 2015)

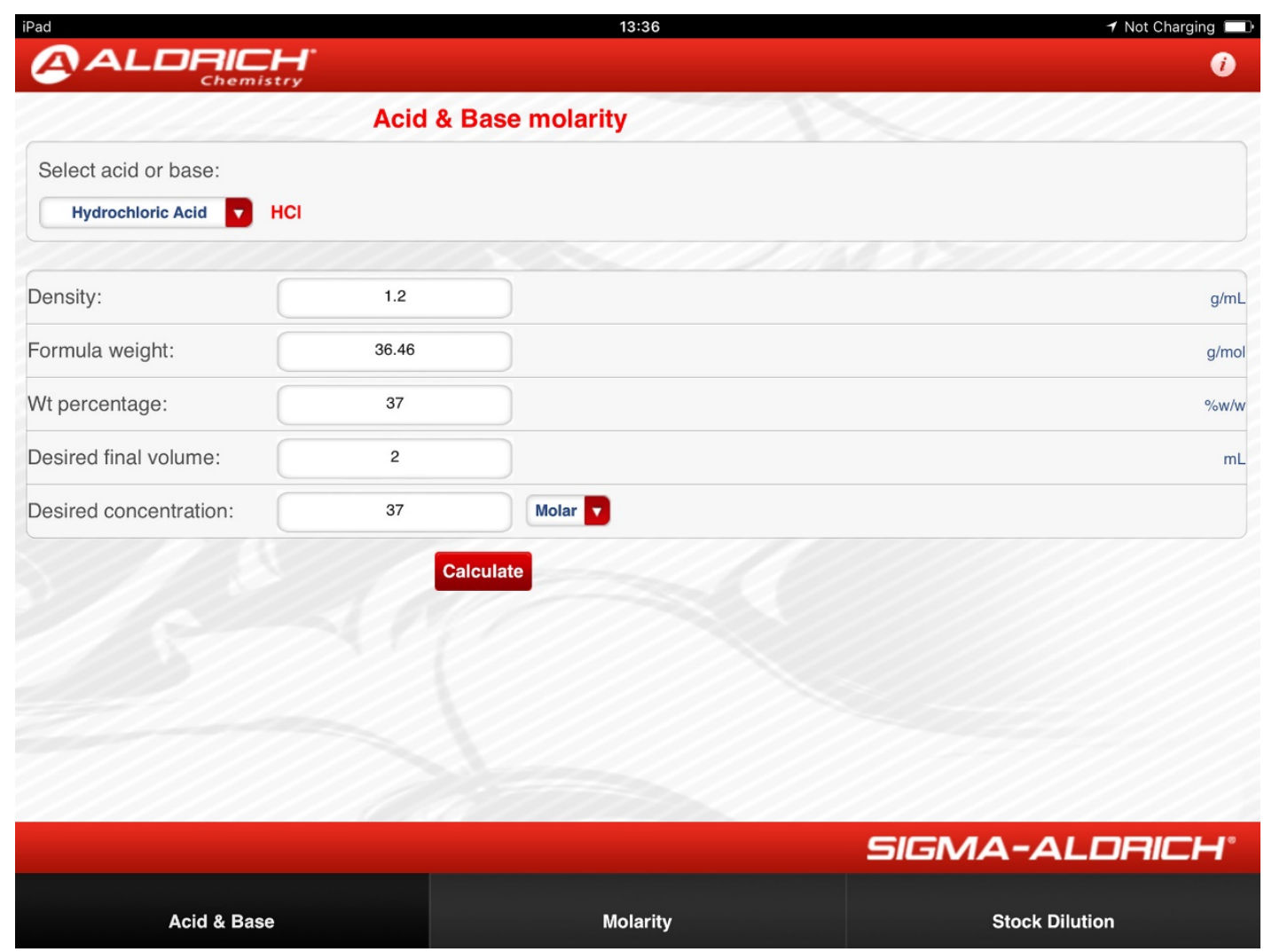

Figure 3. The Acid \& Base start menu (application Molarity @ Sigma-Aldrich Co. 2011)

The application "Chemist" enables experiments with various lab equipment, procedures and chemicals with complete freedom - there is no need to buy chemicals or clean up afterwards. It is perfect for testing, exploring and learning. Apart from the option of conducting experiments using solid, liquid and gassy reagents (Figure 4) and the depicted reaction equation, the application also enables you to measure temperature and the $\mathrm{pH}$ value. 


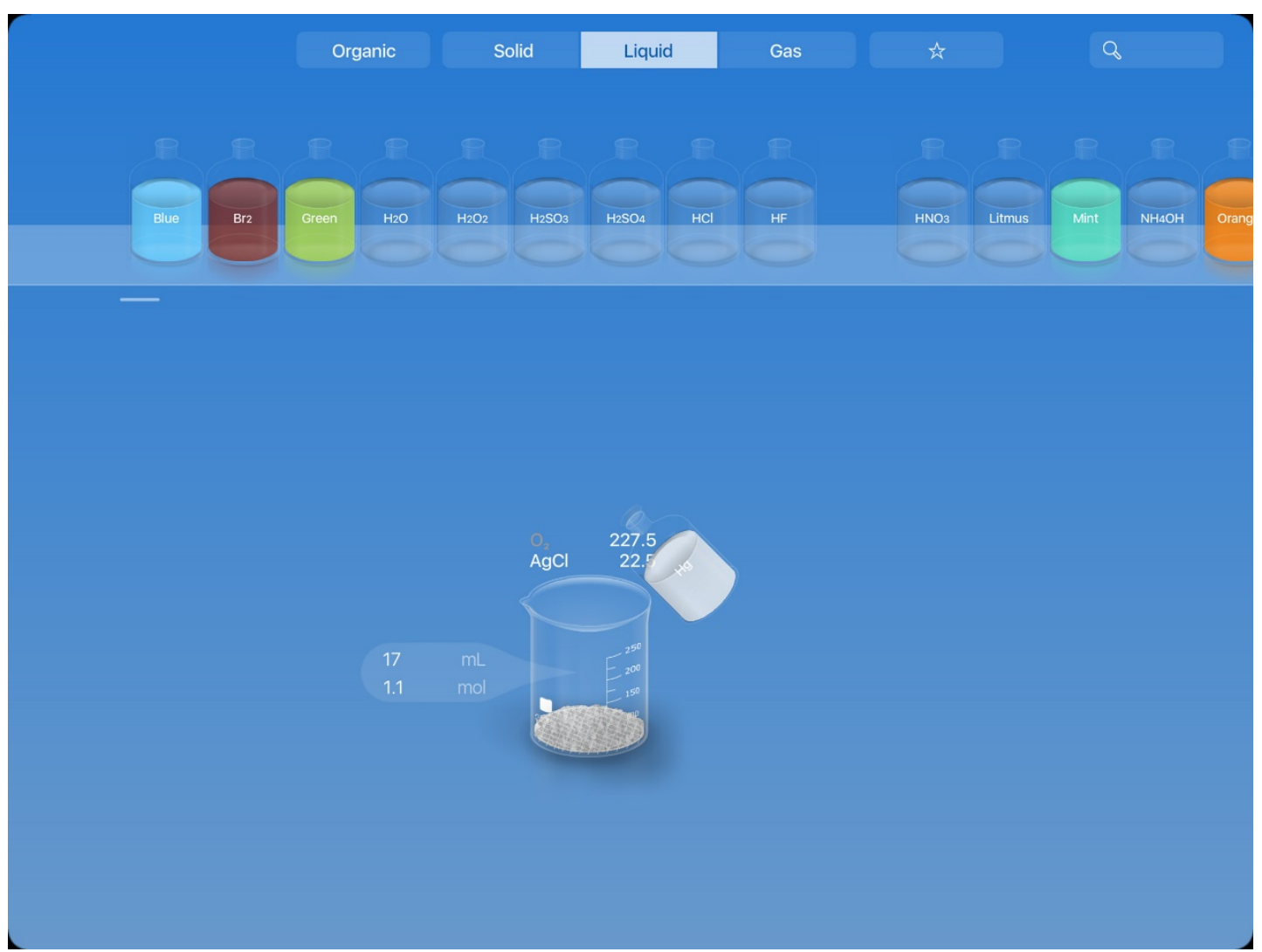

Figure 4. Menu display with the option of selecting solid, liquid and gassy reagents (application Chemist version 5.1.1 @ THIX LLC 2018)

The application "Beaker" turns iPad into a virtual lab to experiment with 150 chemicals. Students can hold it, shake it, heat it up, cap it, add in chemicals, pour out, or pour between BEAKERs via AirMix ${ }^{\mathrm{TM}}$. App can burn chemicals with a match or mix solution with a blender. Using this application gives the teaching process a completely new dimension, it raises interest in the subject matter and also creates new opportunities for active learning and research in combination with experimental work in a real laboratory setting.

\section{Applications in Practical Biology Classes}

When it comes to exercises within the class on Biology, tablet computer applications are used to cover subject matter dealing with Genetics and Cell Structure. When covering the unit dealing with chromosomal mutations, the theoretical part consists of lectures where students are taught on disorders arising from numerical chromosomal mutations, i.e. as a result of extra or missing chromosomes in cells. Trisomies or monosomies, i.e. disorders such as Down syndrome, Edwards syndrome, Patau syndrome, Turner syndrome, etc. occur if such gametes with 24 or 22 chromosomes $(n+1$ or $n-1)$ are formed and fertilized with a gamete containing a normal number of chromosomes $(n=23)$. Practical classes pertaining to the unit "Karyotype and karyogram" begin by microscoping a human chromosome specimen, which is called a karyotype. Students are given an explanation that the human karyogram is made using specimens they are currently observing through a microscope and that possible chromosomal mutations can be seen on them. The prime example they cite and link the answer to the question "Do you know when or which procedure entails making a human karyogram? " is the amniocentesis procedure, in which amniotic fluid is sampled from a pregnant woman and the fetus's karyogram is drawn. After they are done using the microscope, each student is handed out a tablet and using the application "Cytogenetics", i.e. "Diseases and disorders" (Figure 5) and they have to provide answers to the following questions related to this unit:

1. When it comes to the listed disorders, enumerate the main chromosomal mutations by clicking on a particular disorder.

2. What are the most common disorders related to changes in somatic chromosomes (autosomes)? List and write down their genotype (pay particular attention to displaying the overall chromosome number in particular by listing the number of autosomest the number of sex chromosomes).

3. Describe the clinical picture of the most common disorders related to a change in autosome numbers.

4. Which disorders are related to changes in sex chromosomes? Provide a brief description of their symptoms, i.e. the clinical picture and write the genotype for each disorder again.

5. Explain how Klinefelter syndrome and Jacobs syndrome develop respectively.

By clicking on a particular disorder, the student opens the basic disorder description together with a drawing of the chromosomal mutation. An additional click will lead the student to a karyogram pertaining to the stated disorder (Figure 6). It is precisely by using the karyogram that the student should arrive at the answer on the number of chromosomes in a particular disorder, state which chromosome is redundant, determine the overall number of autosomes, i.e. sex chromosomes, describe the basic clinical picture and the rate of occurrence in the general population. 


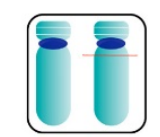

22q11.2 deletion syndrome

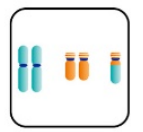

Emanuel syndrome

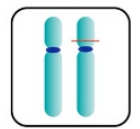

Smith-Magenis syndrome

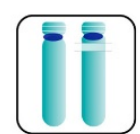

Angelman syndrome

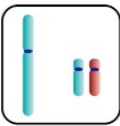

Jacob syndrome

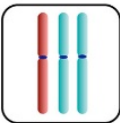

Triploidy

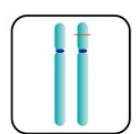

Cri du chat syndrome

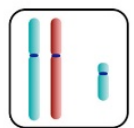

Klinefelter syndrome

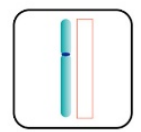

Turner syndrome

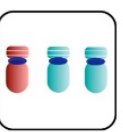

Down syndrome

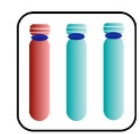

Patau syndrome

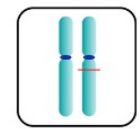

Williams syndrome

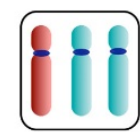

Edwards syndrome

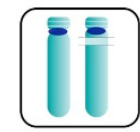

Prader-Willi syndrome

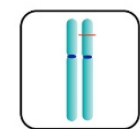

X-linked Ichthyosis

Figure 5. Application Cytogenetics - Diseases and disorders

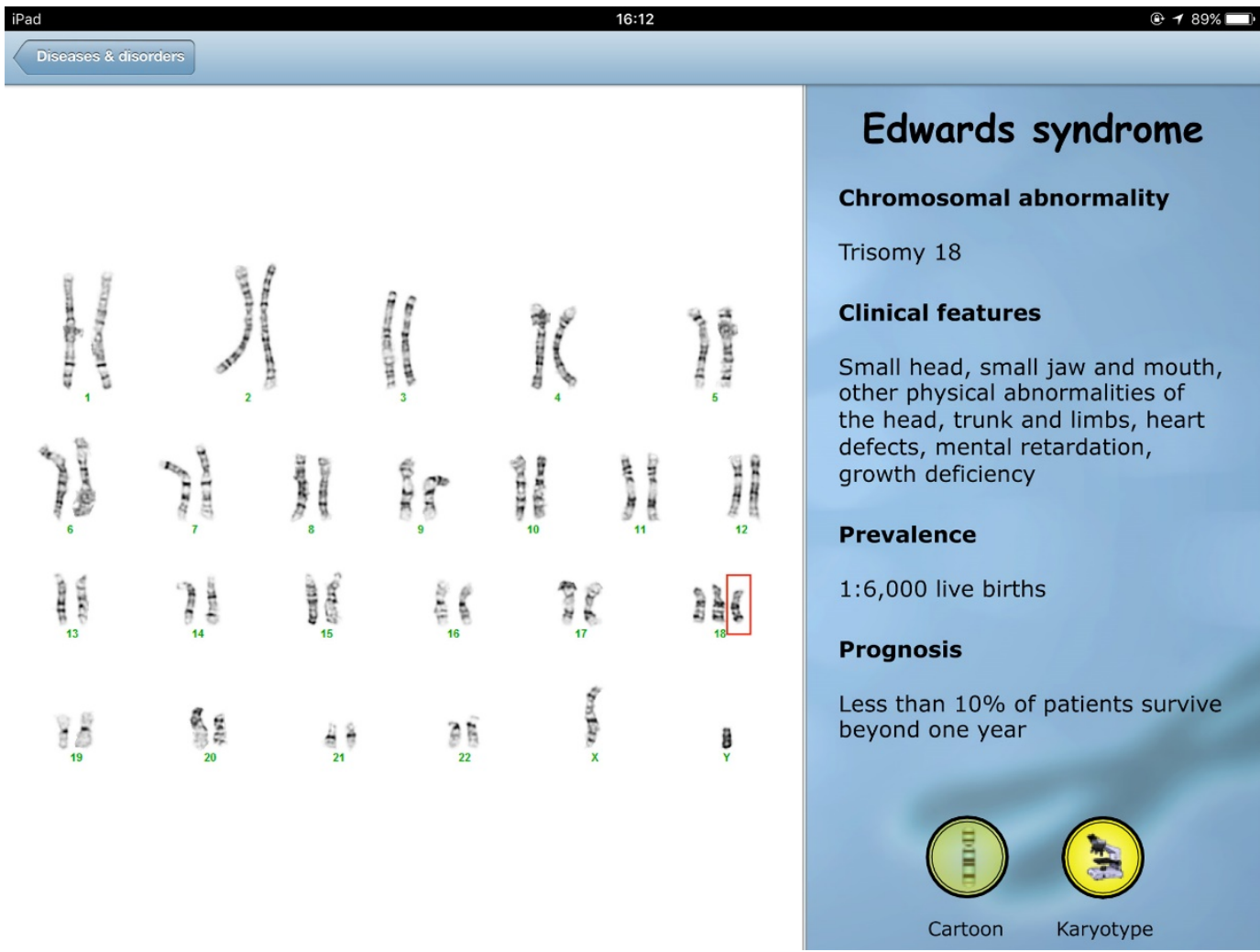

Figure 6. Display of the disorder karyogram (Edwards syndrome)

Students will use the same procedure to determine the characteristics of all other illnesses. Using the following application "Gene screen" students open the "Population genetics" application (Figure 7). The task at hand is to study the mentioned application and give a brief explanation. They also need to answer the question of what this evolutionary force is called. The Population genetics application succinctly explains the evolutionary force called "genetic drift", i.e. "founder effect" whereby, within a few generations, the small original population carrying the mutant allele leads to the forming of a homozygous population, i.e. the prevalence of inbreeding results in fixation of the mutant allele/disorder. Students should come to a conclusion why the application cites the Amish population as an example of this evolutionary force. 


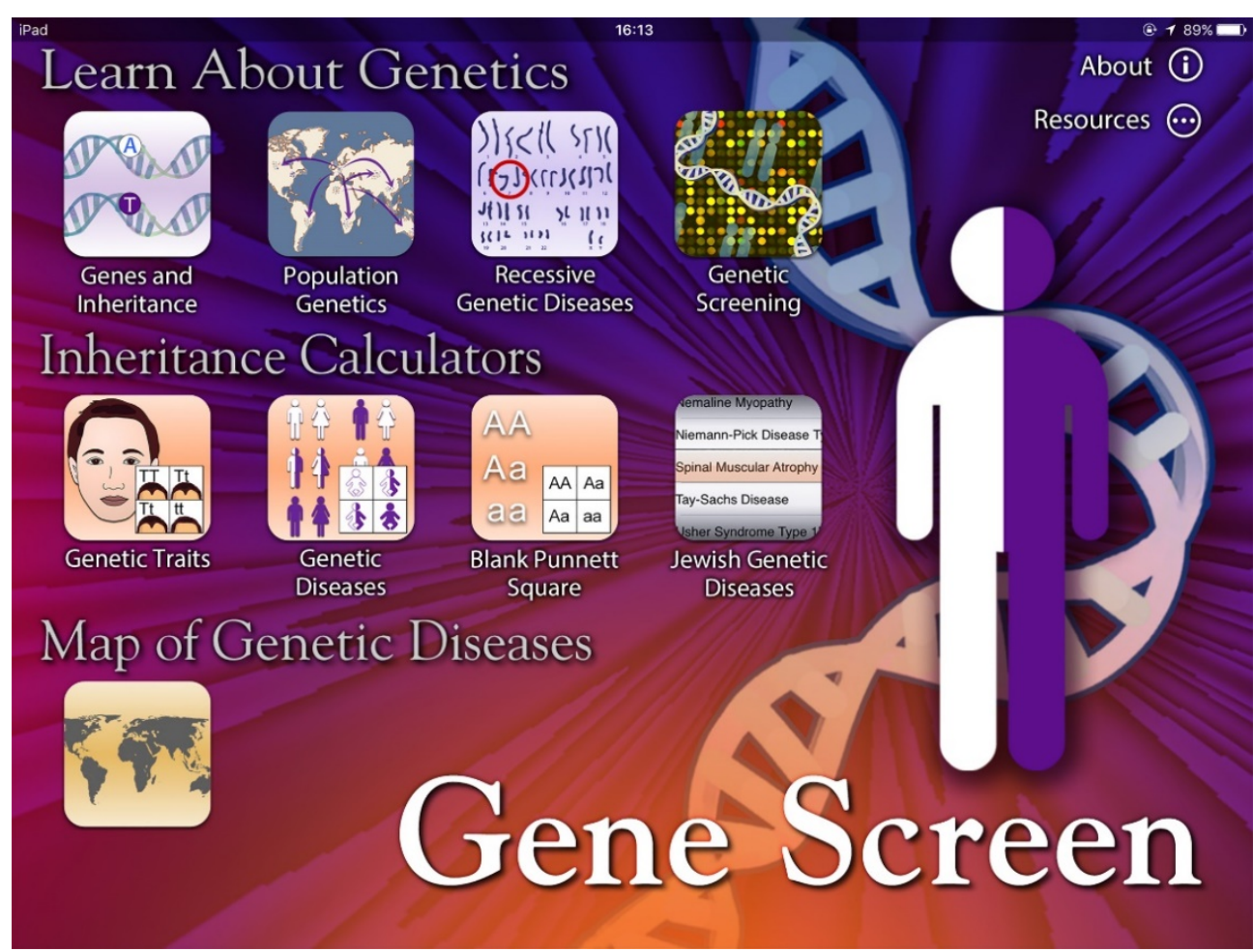

Figure 7. Application Gene Screen (version 1.2 @ Cold Spring Harbor Laboratory 2015)

When it comes to cellular biology and teaching cell structure, students partly find the subject matter to be abstract and have a hard time understanding because not all cell parts can be observed using a cellular microscope (cell structures are often not discernible by light microscopes and their resolution). More specifically, by observing cells using a light microscope, we can notice the cell itself, the cell wall in plant cells and the large nucleus. Other organelles and cell structures take on a granular appearance in the cytoplasm and are not visible. This is why in practical classes we use the "Cell World" application in addition to microscopic observation. By using this application, students are able to enter the level and structure of cell organelles and parts which are not discernible through a microscope. Moreover, the application allows them to move their fingers on the screen and study cell parts they are interested in at that moment. For example, while studying the Golgi apparatus, with the help of the application the student gains an insight into the organelle's structure with a brief description containing the organelle's function appearing sideways (Figure 8).

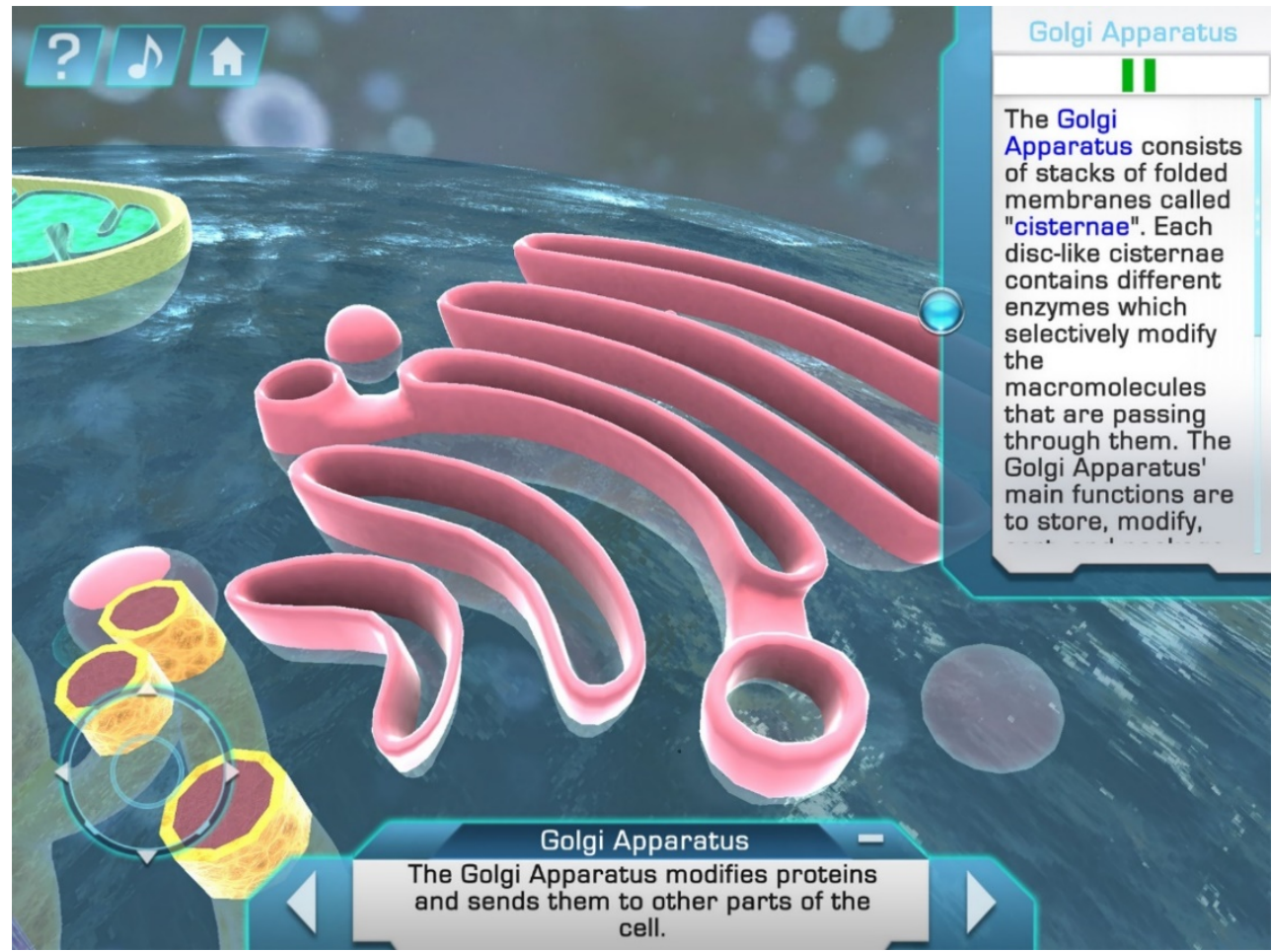

Figure 8. Partial display of the Cell World application with the description of particular organelles (version 1.0.02 @ Virtual Immersive Educational Worlds, Inc. 2014) 


\section{REFERENCES}

Godsk, M. (2013). Tablets for Learning in Higher Education: The Top 10 Affordances. In T. Bastiaens \& G. Marks (Eds.), Proceedings of E-Learn 2013--World Conference on E-Learning in Corporate, Government, Healthcare, and Higher Education, (pp. 1892-1897). Association for the Advancement of Computing in Education (AACE), Las Vegas, NV, USA.

Jennings, G., Anderson, T., Dorset, M., \& Mitchell, J. (2011). Report on the step forward iPad pilot project. Trinity College, The University of Melbourne, Melbourne, Australia.

Lukša, ž., Vuk, S., Pongrac, N., \& Bendelja, D. (2014). Tehnologija u nastavi prirode i društva u osnovnoj školi. Educatio Biologiae $1(1), 27-35$.

Manuguerra, M., \& Petocz, P. (2011). Promoting Student Engagement by Integrating New Technology into Tertiary Education: The Role of the iPad. Asian Social Science, 7(11), 61-65. https://doi.org/10.5539/ass.v7n11p61

Rossing, J., Miller, W., Cecil, A., \& Stamper, S. (2012). iLearning: The future of higher education? Student perceptions on learning with mobile tablets. Journal of the Scholarship of Teaching and Learning, 12(2), 1-26. 